\title{
Erkek yașı sperm parametrelerini etkiliyor mu? Türk popülasyonuna ait ilk seri
}

\author{
Does male age affect sperm parameters? First series from \\ Turkish population
}

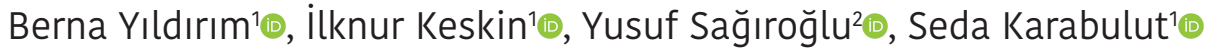

\section{öz}

AMAÇ: Çalışmanın amacı, infertilite araştırma amacıyla elde edilmiş 1402 semen örneğinde, baba yaşı ile semen parametreleri (konsantrasyon, motilite, progresif motilite, morfoloji, akrozomal indeks, semen hacmi) arasındaki ilișkiyi araștırmak ve baba yașının infertilite üzerine olası etkisinin araştırılmasına katkı sağlamaktır.

GEREÇ ve YÖNTEMLER: Çalışma, Ocak 2017-Mayıs 2019 tarihleri arasinda, İstanbul Florence Nightingale Hastanesi, Tüp Bebek Merkezi'ne başvuran ve semen analizi yapılan 1402 hastayı kapsamaktadır. Hastaların semen örnekleri WHO kriterlerine göre değerlendirilmiștir. Örnekler 40 yaş altı ve 40 yaş üstü olacak şekilde iki gruba ayrılmıştır. İki grupta sperm konsantrasyonu $(\mathrm{mil} / \mathrm{mL})$, toplam motilite $(\%)$, progresif motilite (\%), normal morfoloji (\%) ve akrozomal indeks (\%) parametreleri karşılaştırılmıştır.

BULGULAR: İki grup birbiriyle karşılaştırıldığında toplam motilite, progresif motilite, morfoloji ve akrozom indeks parametreleri arasında istatistiksel olarak anlamlı bir fark bulunmamasına rağmen sperm konsantrasyonunun 40 yaş üstü grupta istatistiksel olarak anlamlı derecede yüksek olduğu gözlemlenmiştir $(\mathrm{p}<0,05)$.

SONUC:: İleri anne yașının infertiliteyi etkilediği daha açı olmakla birlikte, ileri baba yaşının infertiliteyle olan ilişkisi günümüzde araştırılmaya devam edilmektedir. Bu çalışma, Türkiye'de bu konuda yapılmış en büyük örneklem kümesine sahip ilk çalışmadır. Bulgular, ileri yaşla birlikte, semen parametrelerinden sperm konsantrasyonunun erkek yaşı ile birlikte arttığını, diğer parametrelerin ise değişmediğini göstermektedir. İleri baba yaşının infertiliteyle ilişkisini anlamak için genetik ve biyokimyasal seviyede daha ileri araştırmalara ihtiyaç vardır.

Anahtar Kelimeler: ileri baba yaşı, semen analizi, infertilite

\section{GíRiș}

Dünya Sağlık Örgütü (WHO) infertiliteyi, herhangi bir korunma yöntemi olmadan, çiftlerin düzenli ilişkiye girmelerine rağmen en az bir yıl boyunca gebeliğin meydana

'İstanbul Medipol Üniversitesi, Tıp Fakültesi, Histoloji ve Embriyoloji Anabilim Dalı, istanbul, Türkiye

${ }^{2}$ Istanbul Florence Nightingale Hastanesi, IVF Merkezi, i̇stanbul, Türkiye

\section{Yazısma Adresi/ Correspondence:}

Dr. Öğr. Üyesi Seda Karabulut

Kavacık Mah. Ekinciler Cad. No.19 Kavacık Kavşağı 34810 Beykoz İstanbul 34810

İstanbul, Türkiye

Tel: $\quad 4448544$

E-mail: sedakarabulut@medipol.edu.tr

Gelis/ Received: $\quad 27.04 .2020$

Kabul/ Accepted: 13.07 .2020

\section{ABSTRACT}

OBJECTIVE: The aim of the study is to investigate the relationship between father age and semen parameters (concentration, motility, progressive motility, morphology, acrosomal index, semen volume) in 1402 semen samples obtained for infertility research and to contribute to the investigation of the possible effect of father age on infertility.

MATRERIAL and METHODS: In our study, 1402 patients who applied to the IVF Center of Istanbul Florence Nightingale Hospital between January 2017 and May 2019 were examined. Semen samples were evaluated according to WHO criteria. Samples were divided into two groups as 40 and over 40 years. Sperm concentration (miles $/ \mathrm{mL}$ ), total motility (\%), progressive motility (\%), normal morphology (\%) and acrosomal index (\%) were compared in two groups.

RESULTS: There was no statistically significant difference between total motility, progressive motility, morphology and acrosome index parameters when the two groups were compared $(p>0.05)$. However, sperm concentration was found to be statistically significant in the group over 40 years of age $(\mathrm{p}<0.05)$.

CONCLUSION: Although it is clear that advanced maternal age affects infertility, the relationship between advanced paternal age and infertility continues to be investigated. Our study includes the largest population from Turkey in this regard. Our results show that, with advanced age, sperm concentration increases with male age, while other parameters do not change. However, further investigations at genetic and biochemical levels are needed to investigate the relationship between advanced age and infertility.

Keywords: advanced male age, semen analysis, infertility

gelmemesi olarak tanımlamaktadır. ${ }^{[1]}$ Herhangi bir korunma yöntemine başvurmayan çiftlerin \%15'i bu durumdan etkilenmektedir. ${ }^{[2]}$ Erkekler, infertilitenin \%20-30'undan tek başına sorumluyken bütün vakaların $\% 50$ 'sine katılmaktadir. $^{[3]}$

Çağımızda kariyer, eğitim, ekonomik ve sosyal nedenlerden dolayı insanlar, daha geç evlenmeye ve çocuk sahibi olmaya yönelmektedir. Son yıllarda erkek infertilitesindeki artı̧ıı bir kısmı çevresel faktörler, sağlık durumu ve yaşam tarzına atfedilmektedir. ${ }^{[4]}$ Stres, yaşlanma, sağlıksız beslenme, fiziksel aktivite yokluğu, kafein, katkı maddeleri ve psikolojik faktörlerin erkek infertilitesini arttırdığı belirtilmiştir. ${ }^{[5]}$ Dizüstü bilgisayar ve cep telefonu vb. teknolojik cihazların sık kullanımı gibi çalışma şartlarına bağlı olarak skrotumun 
ısıya maruz kalması da günümüzde infertilitenin sebepleri arasında gösterilmektedir. ${ }^{[5,6]}$ Erkek infertilitesinin dünya çapında oranı \%2,5 ile \%12 arasında değişmektedir. ${ }^{[3]}$

İleri anne yaşının, infertilite ile olan ilişkisiyle ilgili çok sayıda çalışma bulunmaktadır. Bu çalışmalar, ileri anne yaşının fertiliteyi olumsuz etkilediğini belirtmektedir. ${ }^{[7,8]}$ Ancak ileri baba yaşının, fertilite ile ilişkisi henüz tam olarak ortaya konulamamıştır. ${ }^{[7,9-11]}$ Erkek yaşının infertiliteye neden olmadığı yönünde genel bir görüş olmasına rağmen ${ }^{[9]}$, özellikle son yıllarda erkek yaşı ile sperm parametreleri, sperm fonksiyonu ve genetiği arasındaki ilişkiyi araştıran yayınların sayısında bir artış gözlenmektedir. ${ }^{\text {111-15] }}$ Bu değişikliklerin fertilite üzerindeki olumsuz etkisi ya da gebelik oluşsa bile yeni doğan bebeklerde ortaya çıkarabileceği sorunlar tartışılmaya başlanmıştır. ${ }^{[8,11,16]}$

Semen analizi; erkeğin fertil olup olmadığının değerlendirilmesinde ilk önemli basamaklardan biridir. ${ }^{[11]}$ Semen analiziyle ele alınan sperm sayısı, sperm morfolojisi ve diğer semen parametrelerinin fertilite ile sıkı bir ilişkisi olduğu bilinmektedir. ${ }^{[17,18]}$ Baba yaşının sperm parametrelerine olan etkisini araştıran çalışmaların bir kısmı, ileri baba yaşının sperm hareketliliği, sperm canlılığı ve normal sperm morfolojisi üzerinde negatif etkisi olduğunu ileri sürmüştür. ${ }^{[7,11,19]}$ Yapılan bir çalışmada, WHO kriterlerine en uygun sperm parametrelerinin 30-35 yaş arasında gözlendiği, parametrelerdeki en belirgin azalmanın ise 55 yaşından sonra meydana geldiği ileri sürülmüştür. ${ }^{[20]}$ İleri baba yaşının moleküler boyutta en önemli dezavantajları; spermatogenezin fonksiyonunu değiştirerek DNA hasarı ve kusurlu protamin paketlemesini arttırmak olduğu bildirilmiştir. ${ }^{[11-13,21-24]}$ Ancak, bu bulguların tersine sperm parametrelerinde yaşla birlikte anlamlı bir değişimin olmadığını öne süren çalışmalar da bulunmaktadır. ${ }^{[9,15]}$ Dain ve ark., erkek yaşı ile fertilite ilişkisini ele alan 10 çalışmanın derlemesini yaparak, baba yaşı ile döllenme, implantasyon, gebelik, düşük ve canlı doğum oranları arasında açık bir ilişki olmadığını belirtmişlerdir. ${ }^{[9]}$ Nijs ve ark., IVF ve ICSI tedavisi gören erkeklerde yaptıkları çalışmada, sperm konsantrasyonu, motilite veya morfoloji üzerinde yaşa bağlı herhangi bir değişiklik gözlemediklerini belirtmişlerdir. ${ }^{[15]}$

$\mathrm{Bu}$ çalışmanın amacı, infertilite araştırma amacıyla elde edilmiş 1402 semen örneğinde, baba yaşı ile semen parametreleri (konsantrasyon, motilite, progresif motilite, morfoloji, akrozomal indeks, semen hacmi) arasındaki ilişkiyi araştırmak ve baba yaşının infertilite üzerine olası etkisinin araştırılmasına katkı sağlamaktır.

\section{GEREÇ VE YÖNTEM}

Bu çalışmada, Ocak 2017-Mayıs 2019 tarihleri arasında infertilite araştırması nedeniyle Kadıköy Florence Nightingale Hastanesi Tüp Bebek Merkezi'ne başvuran ve semen analizi yapilan 1402 hasta, retrospektif olarak değerlendirilmişlerdir. Hastalar, Vücut Kitle İndeksi (BMI), meslek vs. gibi herhangi bir elemeye tabi tutulmayıp başvuran tüm hastalar çalışmaya dahil edilmiştir. Azoospermik ve kriptozoospermik hastalar çalışmaya dahil edilmemiştir. Varikosel gibi daha önce herhangi bir testis operasyonu geçirmiş hastalar çalışmanın dışında tutulmuştur. Tüm deneyler aynı (bir) kişi tarafından yapılmıştır.

Hastaların semen örnekleri 3-5 günlük cinsel perhiz süresinin ardından, mastürbasyon yöntemiyle toplanmış ve Dünya Sağlık Örgütü’nün (WHO) 2010 kriterlerine göre bir saat içinde değerlendirilmiştir. ${ }^{[25]}$ Amerikan Üreme Tıbbı Derneği (ASRM), erkekler fertilitesinde 40 yaşı üst sınır olarak belirlemiştir. ${ }^{[26]}$ Ek olarak, literatürde bulunan birçok çalışmada da 40 yaş sınır kabul edilmiştir. ${ }^{\text {[27- }}$ ${ }^{32]} \mathrm{Bu}$ nedenle, çalışmaya alınan hastalar 40 yaş ve altı ve 40 yaş üstü olmak üzere iki gruba ayrılmıştır. Çalışmanın etik kurul onayı, İstanbul Medipol Üniversitesi Girişimsel Olmayan Klinik Araştırmalar Etik Kurulu'ndan alınmıştır (19/08/2019-10840098-604,01,01-E. 41146).

\section{Semen Analizlerinin Yapılması}

Semen örnekleri steril toplama kabına alınıp, 10-30 dakikalık likefaksiyon süresini takiben bir saat içinde Dünya Sağlık Örgütü’nün WHO 2010 kriterlerine göre analiz edilmiştir. ${ }^{[25]}$ Öncelikle sperm hacmi (mL) ile pH'sı ölçülmüş ve görünümü not edilmiştir.

\section{Sperm Konsantrasyonu}

Makler sperm sayma kamarasına $10 \mu \mathrm{L}$ semen örneği koyulmuştur. Faz kontrast mikroskobunda 20X objektif altında 100 karedeki sperm hücreleri sayılarak, sonuç mil/ $\mathrm{mL}$ olarak verilmiştir.

\section{Motilite Parametreleri}

Makler sperm sayma kamarasına $10 \mu \mathrm{l}$ semen örneği koyulmuştur. Faz kontrast mikroskobunda 40X objektif altında en az 100 sperm sayılarak spermler dört gruba ayrılmıştır. A motilite progresif motil (ileri hızlı hareketli) spermler için, B motilite yavaş hareketli spermler için, C motilite yerinde hareketli spermler için ve D motilite hareketsiz spermler için olacak şekilde gruplanmış ve sonuçlar yüzde (\%) olarak verilmiştir. A, B ve C motilite oranları toplamı toplam motiliteyi, A motilite oranı ise progresif motil sperm oranı olarak verilmiştir.

\section{Morfoloji ve Akrozomal indeks}

$10 \mu \mathrm{l}$ semen örneği yayma şeklinde lama yayılarak kurutulmuş ve Diff-3 boyası ile boyanmıştır. Boyama işleminden önce yayma örnekleri fikse edilmiştir. Hemen ardından iki farklı boyama solüsyonunda 30 saniye bekletilerek 
boyanmış ve kurutulmuştur. Çalışılan örnek, boyamanın ardından 100X immersiyon yağlı objektif altında Kruger's Strict Criteria kullanılarak analiz edilmiştir. En az 100 sperm hücresi sayılarak morfolojik olarak normal spermler ile anormal spermler ayrılmış ve sonuç yüzde (\%) şeklinde normal sperm oranı olarak verilmiştir. Akrozomal indeks için akrozomlar değerlendirilmiş ve en az 100 sperm hücresi sayılmıştır. Morfolojik olarak normal akrozomlar ile anormal akrozomlar ayrılmıs, sonuç ise normal akrozomal indeks oranı yüzde (\%) olarak verilmiştir.

\section{İstatistiksel Analiz}

Veriler, SPSS 22,0 software for Windows kullanılarak Mann-Whitney U Test ile karşılaştırılmıştır. $p<0,05$ değeri anlamlılık seviyesi olarak kabul edilmiştir. Sonuçlar ortala$\mathrm{ma} \pm \mathrm{SD}$ olarak verilmiştir.

\section{BULGULAR}

Semen parametreleri istatistiksel olarak değerlendirildiğinde; 40 yaş altı ve 41 yaş üstü hastaların semen parametreleri Tablo 1'de gösterilmiştir. Toplam motilite, progresif motilite, normal morfoloji ve akrozom indeksi parametrelerinde iki grup arasında istatistiksel olarak anlamlı derecede bir farklılık gözlenmemiş $(p>0,05)$, sperm konsantrasyonunun 40 yaş üstünde, istatistiksel olarak anlamlı derecede arttığı gözlenmiştir $(p<0,05)$ (Şekil 1$)$.

\begin{tabular}{cccccc}
\multicolumn{6}{c}{ Tablo 1. Her iki yaş grubunun sperm parametreleri } \\
Gruplar $\begin{array}{c}\text { Sperm } \\
\text { konsantrasyonu } \\
\text { (mil/mL) }\end{array}$ & $\begin{array}{c}\text { Toplam } \\
\text { motilite }(\%)\end{array}$ & $\begin{array}{c}\text { Progresif } \\
\text { motilite } \\
(\%)\end{array}$ & $\begin{array}{c}\text { Normal } \\
\text { morfoloji } \\
(\%)\end{array}$ & $\begin{array}{c}\text { Akrozomal } \\
\text { indeks (\%) }\end{array}$ \\
\hline$\leq 40$ yaş & $76,09 \pm 38,4$ & $66,20 \pm 18$ & $11,37 \pm 8,5$ & $2,30 \pm 0,9$ & $79,54 \pm 12,1$ \\
$>41$ yaş & $85,35 \pm 51,4$ & $65,92 \pm 22,1$ & $11,69 \pm 10,6$ & $2,31 \pm 0,72$ & $79,26 \pm 19,4$ \\
p değeri & $<0,05$ & $>0,05$ & $>0,05$ & $>0,05$ & $>0,05$
\end{tabular}

$\leq 40$ yaş ve $>41$ yaş gruplarının sperm parametreleri. Değerler, ortalama \pm SD olarak verilmiştir.

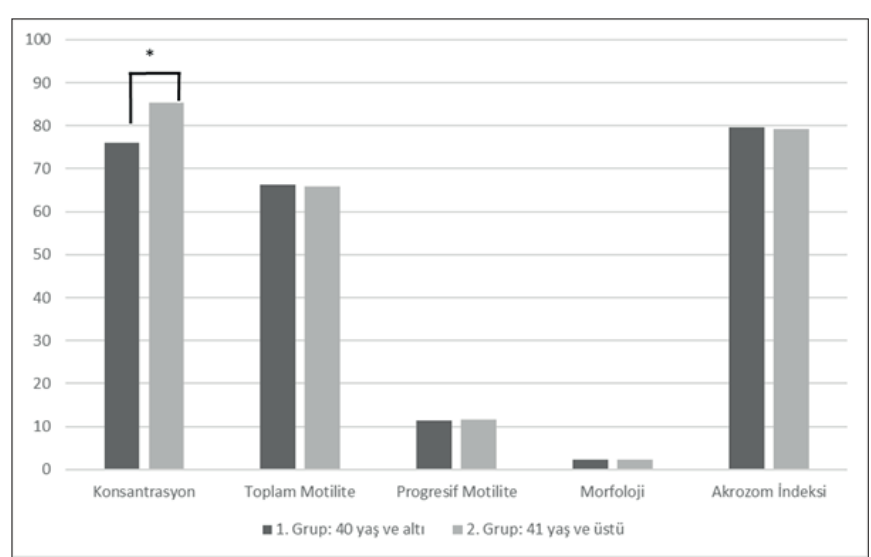

Şekil 1. Erkek yaşının, sperm parametrelerine etkisi (Konsantrasyon: mil/mL, Toplam Motilite: \%, Progresif Motilite: \%, Morfoloji: \%, Akrozom İndeksi: \% olarak verilmiştir).

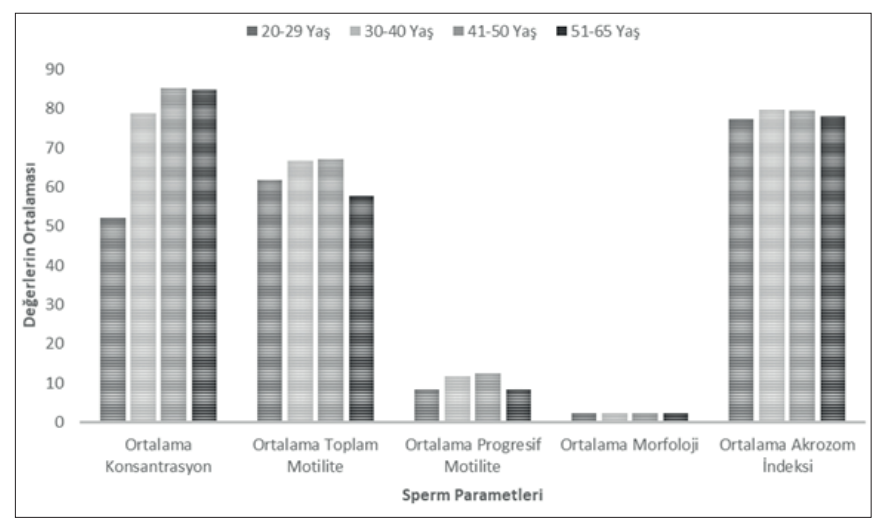

Şekil 2. Sperm parametrelerinin yaş alt gruplarına göre ayrııması.

Çalışmaya alınan hastalar dekatlara göre tekrar gruplandırıldığında, sperm konsantrasyonunun yaşla birlikte arttığı gözlenmiştir (Şekil 2).

\section{TARTIȘMA}

Son yıllarda, sperm parametreleri ile ileri baba yaşı arasındaki ilişkiyi araştıran çalışmaların sonuçları tartışmalıdır. [33-38] Yapılan bir çalışmada, semen parametrelerinin 34 yaşına dek değişmediği 34 yaşından sonra ise sperm sayısının azaldığı bildirilmiştir. ${ }^{[27]}$ Aynı çalışmada sperm konsantrasyonunun, normal morfolojili sperm yüzdesinin ve ileri hareketli sperm yüzdesinin 40 yaşında azaldığı, toplam motilitenin 43 yaşında azaldığı ve semen hacminin 45 yaşında azaldığı ileri sürülmüşsür. ${ }^{[27]}$ Başka bir çalışmada ise $21-50$ yaş arası grupta sperm üretiminin 51 yaş sonrası gruba göre \%30 daha yüksek olduğu gözlenmiştir. ${ }^{[39]} \mathrm{Bu}$ çalışmaların ortak noktaları ise ilerleyen erkek yaşıyla birlikte semen parametrelerinin infertiliteyle doğru orantılı olacak şekilde olumsuz yönde değişim görülmesidir.

Sperm parametreleri sırayla ele alındığında; akrozom indeksi ve progresif motilitenin ileri yaş ile ilişkisini ele alan çalışmaların birinde 25-55 yaş arası erkeklerde akrozom indeksinin artan yaşa bağlı olarak değişmediği ancak progresif motilitenin artan yaş ile azaldığı bildirilmiştir. ${ }^{[20]}$ Erkeklerin yaş ortalamaları 50,3 ve 32,2 olacak şekilde iki farklı gruba ayrıldığı bir başka çalışmada; akrozom indeksi ve progresif motilitenin gruplar arasında istatistiksel olarak farklı olmadıkları belirtilmiştir. ${ }^{[40]}$ Yaptığımız çalışmada, iki grup arasında progresif motilite ve akrozom indeksi parametrelerinde farklılık gözlenmemiştir (Şekil 1). 40 yaş altı hasta grubunun yaş ortalaması 34,2 ve 41 yaş üstü hasta grubunun yaş ortalaması 45 'tir. Bu sonuç, iki grubun yaş ortalamalarının birbirine yakın olması sebebiyle akrozom indeksi ve progresif motilite parametrelerinde fark gözlenmediğini düşündürmektedir.

Toplam motilite incelendiğinde; $18-76$ yaş aralığında 5.000'den fazla erkeğin semen parametrelerinin değerlendirildiği bir çalışmada, toplam motilite ile yaş arasında 
negatif korelasyon olduğu belirtilmiştir. ${ }^{[28]}$ Dahası, semen parametrelerinin 40 yașından sonra istatistiksel olarak anlamlı bir şekilde olumsuz yönde değiştiğini öne sürmüşlerdir. ${ }^{[4]}$ Bahsi geçen çalışmada, değerlendirmeye alınan hastaların yaş aralığının bizim çalışmamızın aksine çok geniş tutulması ve 5000'den fazla hasta bulunması, toplam motilitenin yaşla birlikte azaldığı sonucuna varılmasına sebep olmuş olabilir. Çalışmamızın sonucunda iki grup arasındaki toplam motilite karşılaştırıldığında fark gözlenmemiştir (Şekil 1). Çalışmaya alınan hastaların yaşları 22-51 yaş arasında değişmektedir. Çalışmaya alınan tüm hastaların yaşlarının birbirine yakın olması sebebiyle fark gözlenmediği düşünülmektedir.

Başka bir parametre olan sperm morfolojisi ele alındığında, IVF veya ICSI tedavisi gören 278 hastanın semen parametrelerinin incelendiği bir çalışmada, sperm morfolojisi ile yaş arasında anlamlı bir ilişki gözlemlenmediği belirtilmiştir. ${ }^{[15]}$ Semen parametrelerinin yaş ile ilişkisini araştıran başka çalışmalar ileri erkek yaşı ve sperm morfolojisinin yaşla birlikte azalmadığı görüşü öne sürülmüştür. ${ }^{[9]}$ Bazı çalışmalarda ise erkek yaşı arttıkça semen hacminin, sperm hareketliliğinin ve normal morfoloji sperm yüzdesinin düşme eğiliminde olduğu belirtilmiştir. ${ }^{[10,41]}$ Çalışmamızın sonucunda iki grup arasında normal sperm morfolojisi açısından fark gözlenmemiştir (Şekil 1). Hastaların yaşlarının yakın olması sebebiyle, spermlerinin benzer bir morfolojiye sahip olduğu ve anormal morfolojili sperm yüzdesinin düşük olduğu düşünülmektedir.

Sperm konsantrasyonu ele alındığında, Levitas ve ekibi, yaşlanma ile ilgili sperm konsantrasyonunda kademeli bir artış gösterdiğini ve her 5 yaş için sperm konsantrasyonunda $\% 3$ ile $\% 8,3$ arasında bir artış olduğunu iddia etmişlerdir. ${ }^{[42]}$ Brahem ve ekibi, yaptıkları çalışmada hasta grubunda sperm hacmi ve canlılığı yaşla birlikte istatistiksel olarak anlamlı derecede azalırken, sperm konsantrasyonunun yaşla birlikte istatistiksel olarak anlamlı derecede arttığını ileri sürmüşlerdir. ${ }^{[10]} \mathrm{Bu}$ çalışmada ise sperm konsantrasyonunun erkek yaşıyla birlikte arttığı tespit edilmiştir (Şekil 1). Bu sonuç, literatürde bulunan bir kaç çalışmanın sonuçlarını doğrular niteliktedir. ${ }^{[10,11,20]}$ Her ne kadar sperm konsantrasyonunun yaş ile birlikte arttı̆̆g tespit edilse de literatürde sperm konsantrasyonunun azaldığını söyleyen, ${ }^{[40,43,44]}$ hatta artan yaş ile sperm konsantrasyonu arasında tutarlı bir ilişki bulunmadığı sonucuna varan çalışmalar da mevcuttur. ${ }^{[9,19,33,45,46]}$ Fakat, literatürde sperm konsantrasyonunun yaş ile arttığ1 sonucunu destekleyen çalışmalar sayıca daha fazladır. ${ }^{[34,47-52]}$

Her ne kadar ulaşılan sonuç literatürü desteklese de yaş gruplarının ve etnik kökenlerin farklı olması, örneklem büyüklüğünün değişken olması ve cinsel yoksunluk süresi yapılan çalışmaların sonuçlarının kısmen değişmesine neden olabilmektedir. ${ }^{[53,54]}$ Bu çalışmanın sperm konsantrasyonu için elde edilen verileri diğer çalışmaların sonuçlarını destekler nitelikte olsa da çalışılan grupların, yaş aralıkları ve hasta sayıları çalışmalar arasında değişkenlik göstermektedir. Farklı yaş ortalamalarına sahip, farklı coğrafik bölgelere ait daha fazla sayıda örnekleme üzerinde çalışmaya ihtiyaç duyulmaktadır. Bu çalışma, Türkiye'de bu konuda yapılmış en geniş hasta sayısına sahip çalışma olması açısından önem arz etmektedir. Fakat hastaların herhangi bir sınıflandırma yapılmadan tümünün çalışmaya alınması çalışmanın kısıtlılı̆̆ıdır.

Elde edilen bulgular doğrultusunda, semen parametrelerinden en önemlilerinden biri olan sperm konsantrasyonunun erkek yaşı ile birlikte arttığı, diğer parametrelerin ise değişmediği belirlenmiştir. Bu doğrultuda baba yaşının semen parametreleri üzerine olumsuz etki etmediği görülmektedir. Ancak, semen parametrelerinin erkek infertilitesinde tek etken olmadığı bilindiğinden konunun moleküler ve genetik seviyede yapılan daha ileri çalışmalarla araştırılması gerekmektedir. Ayrıca farklı yaş aralıkları ve farklı demografik özelliklere göre sınıflandırılmış gruplarla yapılacak çalışmalara ihtiyaç duyulmaktadır.

\section{Etik Kurul Onayı}

Çalışma, İstanbul Medipol Üniversitesi Girişimsel Olmayan Klinik Araştırmalar Etik Kurulu tarafından onaylandı. (onay tarihi ve sayısı: 19/08/2019-10840098-604,01,01-E. 41146).

Hakem Değerlendirmesi

Dış bağımsız.

Çıkar Çatışması

Yazarlar çıkar ilişkisi olmadığını beyan etmişlerdir.

\section{Finansal Destek}

Herhangi bir mali destek alınmamıştır.

\section{Ethics Committee Approval}

The study was approved by Istanbul Medipol University Non-Interventional Clinical Research Ethics Committee. (date and number of approval: 219/08/2019-10840098604,01,01-E. 41146).

\section{Peer-review}

Externally peer-reviewed.

Conflict of Interest

No conflict of interest was declared by the authors.

Financial Disclosure

No financial support has been received.

\section{KAYNAKLAR}

1. Zegers-Hochschild F, Adamson GD, de Mouzon J, Ishihara O, Mansour R, Nygren K, et al. The international committee for monitoring assisted reproductive technology (ICMART) and the World Health Organization (WHO) revised glossary on ART terminology, 2009. Hum Reprod 2009;24:2683-7. [CrossRef]

2. Sharlip ID, Jarow JP, Belker AM, Lipshultz LI, Sigman M, Thomas AJ, et al. Best practice policies for male infertility. Fertil Steril 2002;77:873-82. [CrossRef]

3. Agarwal A, Mulgund A, Hamada A, Chyatte MR. A unique view on male infertility around the globe. Reprod Biol Endocrinol 2015;13:37. [CrossRef]

4. Kesari KK, Agarwal A, Henkel R. Radiations and male fertility. Reproductive Biology and Endocrinology 2018;16:118. [CrossRef] 
5. Ilacqua A, Izzo G, Emerenziani GP, Baldari C, Aversa A. Life style and fertility: the influence of stress and quality of life on male fertility. Reprod Biol Endocrinol 2018;16:115. [CrossRef]

6. Du Plessis SS, Agarwal A, Sabanegh ES Jr, editors. Male infertility: a complete guide to life style and environmental factors. Cleveland, OH, USA: Springer ;2014. [CrossRef]

7. Humm KC, Sakkas D. Role of increased male age in IVF and egg donation: is sperm DNA fragmentation responsible? Fertil Steril 2013;99:30-6. [CrossRef]

8. Jenkins TG, Aston KI, Pflueger C, Cairns BR, Carrell DT. Age-associated sperm DNA methylation alterations: possible implications in offspring disease susceptibility PLoS Genet 2014;10:e1004458. [CrossRef]

9. Dain L, Auslander R, Dirnfeld M. The effect of paternal age on assisted reproduction outcome. Fertil Steril 2011;95:1-8. [CrossRef]

10. Brahem S, Mehdi M, Elghezal H, Saad A. The effects of male aging on semen quality, sperm DNA fragmentation and chromosomal abnormalities in an infertile population. J Assist Reprod Genet 2011;28:425-32. [CrossRef]

11. Sharma R, Agarwal A, Rohra VK, Assidi M, Abu-Elmagd M, Turki RF. Effects of increased paternal age on sperm quality, reproductive outcome and associated epigenetic risks to offspring. Reprod Biol Endocrinol 2015;13:35. [CrossRef]

12. Singh NP, Muller CH, Berger RE. Effects of age on DNA double-strand breaks and apoptosis in human sperm. Fertil Steril 2003;80:1420-30. [CrossRef]

13. Simon L, Castillo J, Oliva R, Lewis SE. Relationships between human sperm protamines, DNA damage and assisted reproduction outcomes. Reprod Biomed Online 2011;23:724-34. [CrossRef]

14. Das M, Al-Hathal N, San-Gabriel M, Phillips S, Kadoch IJ, Bissonnette $\mathrm{F}$, et al. High prevalence of isolated sperm DNA damage in infertile men with advanced paternal age. J Assist Reprod Genet 2013;30:843-8. [CrossRef]

15. Nijs M, De Jonge C, Cox A, Janssen M, Bosmans E, Ombelet W. Correlation between male age, WHO sperm parameters, DNA fragmentation, chromatin packaging and outcome in assisted reproduction technology. Andrologia 2011;43:174-9. [CrossRef]

16. Milekic MH, Xin Y, A O’Donnell, Kumar KK, Bradley-Moore M, Malaspina D, et al. Age-related sperm DNA methylation changes are transmitted to offspring and associated with abnormal behavior and dysregulated gene expression. Mol Psychiatry 2015;20:9951001. [CrossRef]

17. Colasante A, Minasi MG, Scarselli F, Casciani V, Zazzaro V, Ruberti A, et al. The aging male: Relationship between male age, sperm quality and sperm DNA damage in an unselected population of 3124 men attending the fertility centre for the first time. Arch Ital Urol Androl 2018;90:254-9. [CrossRef]

18. Ok E, Özyurt D, Gülekli B. Asthenozoospermia olgularında sperm morfolojisi değerlendirmede Spermac ve Diff-quik boya yöntemlerinin karşılaştırılması. Gülhane Tıp Derg 2008;50:23-6. http://cms.galenos. com.tr/Uploads/Article_33204/GMJ-50-23-En.pdf

19. Kidd SA, Eskenazi B, Wyrobek AJ. Effects of male age on semen quality and fertility: a review of the literature. Fertil Steril 2001;75:237-48. [CrossRef]

20. Levitas E, Lunenfeld E, Weisz N, Friger M, Potashnik G. Relationship between age and semen parameters in men with normal sperm concentration: analysis of 6022 semen samples. Andrologia 2007;39:45-50. [CrossRef]

21. Carrell DT, Liu L. Altered protamine 2 expression is uncommon in donors of known fertility, but common among men with poor fertilizing capacity, and may reflect other abnormalities of spermiogenesis. J Androl 2001;22:604-10. [CrossRef]
22. Aoki VW, Moskovtsev SI, Willis J, Liu L, Mullen JBM, Carrell DT. DNA integrity is compromised in protamine-deficient human sperm. J Androl 2005;26:741-8. [CrossRef]

23. Aoki VW, Emery BR, Liu L, Carrell DT. Protamine levels vary between individual sperm cells of infertile human males and correlate with viability and DNA integrity. J Androl 2006;27:890_ 8. [CrossRef]

24. Zubkova EV, Wade M, Robaire B. Changes in spermatozoal chromatin packaging and susceptibility to oxidative challenge during aging. Fertil Steril 2005;84:1191-8. [CrossRef]

25. Cooper TG, Noonan E, von Eckardstein S, Auger J, Baker HWG, Behre HM, et al. World Health Organization reference values for human semen characteristics. Hum Reprod Update 2010;16:23145. [CrossRef]

25. Gray A, Feldman HA, Mckinlay JB, Longcope C. Age disease and changing sex hormone levels in middle-aged men: results of the Massachusetts Male Aging Study. J Clin Endocrinol Metab 1991;73:1016-25. [CrossRef]

26. The American Society for Reproductive Medicine. Guidelines for Sperm Donation. Fertil Steril 2002;77:2-5. [CrossRef]

27. Stone BA, Alex A, Werlin LB, Marrs RP. Age thresholds for changes in semen parameters in men. Fertil Steril 2013;100:952-8. [CrossRef]

28. Verón GL, Tissera AD, Bello R, Beltramone F, Estofan G, Molina RI, Vazquez-Levin MH. Impact of age, clinical conditions, and lifestyle on routine semen parameters and sperm kinematics. Fertil Steril 2018;110:68-75.e4. [CrossRef]

29. Ford WCL, North K, Taylor H, Farrow A, Hull MGR, Golding $\mathrm{J}$; the ALSPAC StudyTeam. Increasing paternal age is associated with delayed conception in a large population of fertile couples: evidence for declining fecundity in older men. Hum Reproduction 2000;15:1703-8. [CrossRef]

30. Zhu QX, Meads C, Lu ML, Wu JQ, Zhou WJ, Gao ES. Turning point of age for semen quality: a population-based study in Chinese men. Fertil Steril 2011;96:572-6. [CrossRef]

31. Marcon L, Boissonneault G. Transient DNA strand breaks during mouse and human spermiogenesis: new insights in stage specificity and link to chromatin remodeling. Biol Reprod 2004;70:910-8. [CrossRef]

32. de la Rochebrochard E, Mcelreavey K, Thonneau P. Paternal age over 40 years: the "amber light" in the reproductive life of men? 2003;24:459-65. [CrossRef]

33. Schwartz D, Mayaux MJ, Spira A, Moscato ML, Jouannet P, Françoise Czyglik, David G. Semen characteristics as a function of age in 833 fertile men. Fertil Steril 1983;39:530-5. [CrossRef]

34. Irvine S, Cawood E, Richardson D, MacDonald E, Aitken J. Evidence of deteriorating semen quality in the United Kingdom: birth cohort study in 577 men in Scotland over 11 years. BMJ 1996;312:467-71. [CrossRef]

35. Spandorfer SD, Avrech OM, Colombero LT, Palermo GD, Rosenwaks Z. Effect of parental age on fertilization and pregnancy characteristics in couples treated by intracytoplasmic sperm injection. Hum Reprod 1998;13:334-8. [CrossRef]

36. Berling S, Wölner-Hanssen P. No evidence of deteriorating semen quality among men in infertile relationships during the last decade: a study of males from Southern Sweden. Hum Reprod (Oxford, England) 1997;12:1002-5. [CrossRef]

37. Wang C, Chan SYW, Leung A, Ng RP, Ng M, Tang LCH, et al. Cross-sectional study of semen parameters in a large group of normal Chinese men. Int J Androl 1985;8:257-74. [CrossRef]

38. Auger J, Kunstmann JM, Czyglik F, Jouannet P. Decline in semen quality among fertile men in Paris during the past 20 years. New Engl J Med 1995;332:281-5. [CrossRef] 
39. Johnson L, Petty CS, Neaves WB. Influence of age on sperm production and testicular weights in men. Reproduction 1984;70:211-8. [CrossRef]

40. Haidl G, Jung A, Schill WB. Ageing and sperm function. Hum Reprod 1996;11:558-60. [CrossRef]

41. Agarwal A, Sekhon LH. Oxidative stress and antioxidants for idiopathic oligoasthenoteratospermia: is it justified? Indian J Urol 2011;27 1:74. [CrossRef]

42. Levitas E, Lunenfeld E, Weiss N, Friger M, Har-Vardi I, Koifman A, Potashnik G. Relationship between the duration of sexual abstinence and semen quality: analysis of 9,489 semen samples. Fertil Steril 2005;83:1680-6. [CrossRef]

43. Eskenazi B, Wyrobek AJ, Sloter E, Kidd SA, Moore L, Young S, Moore D. The association of age and semen quality in healthy men. Hum Reprod 2003;18:447-54. [CrossRef]

44. Centola GM, Eberly S. Seasonal variations and age-related changes in human sperm count, motility, motion parameters, morphology, and white blood cell concentration. Fertil Steril 1999;72:803-8. [CrossRef]

45. Gallardo E, Simón C, Levy M, Guanes PP, Remohí J, Pellicer A. Effect of age on sperm fertility potential: oocyte donation as a model. Fertil Steril 1996;66:260-4. [CrossRef]

46. Aboulghar M, Mansour R, Al-Inany H, Abou-Setta AM, Aboulghar M, Mourad L, Serour G. Paternal age and outcome of intracytoplasmic sperm injection. Reprod Biomed Online 2007; 14:588-92. [CrossRef]
47. Fisch H, Goluboff ET, Olson JH, Feldshuh J, Broder SJ, Barad DH. Semen analyses in 1,283 men from the United States over a 25-year period: no decline in quality. Fertil Steril 1996;65:100914. [CrossRef]

48. Rolf C, Behre HM, Nieschlag E. Reproductive parameters of older compared to younger men of infertile couples. Int J Androl 1996;19:135-42. [CrossRef]

49. Nieschlag E, Lammers U, Freischem CW, Langer K, Wickings EJ. Reproductive functions in young fathers and grandfathers. J Clin Endocrinol Metab 1982;55:676-81. [CrossRef]

50. Singer R, Sagiv M, Levinsky H, Allalouf D. Andrological parameters in men with high sperm counts and possible correlation with age. Arch Androl 1990;24:107-11. [CrossRef]

51. Andolz P, Bielsa MA, Vila J. Evolution of semen quality in Northeastern Spain: a study in 22759 infertile men over a 36 year period. Hum Reprod 1999;14:731-5. [CrossRef]

52. Bujan L, Mansat A, Pontonnier F, Mieusset R. Time series analysis of sperm concentration in fertile men in Toulouse, France between 1977 and 1992. BMJ 1996;312:471-2. [CrossRef]

53. Guzick DS, Overstreet JW, Factor-Litvak P, Brazil CK, Nakajima ST, Coutifaris C, et al. Sperm morphology, motility, and concentration in fertile and infertile men. New Engl J Med 2001;345:1388-93.

54. Keel BA. Within and between subject variation in semen parameters in infertile men and normal semen donors. Fertil Steril 2006;85:128-34. [CrossRef] 